Journal of Engineering and Applied Sciences 14 (Special Issue 2): 5533-5540, 2019

ISSN: $1816-949 \mathrm{X}$

(C) Medwell Journals, 2019

\title{
Modal Analysis of Castellated Steel IPE Section
}

\author{
Bahaa Hussein Al-Abbas, Ali Ghanim Abbas AL-Khafaji and Sadjad A. Hemzah \\ College of Engineering, University of Kerbala, 56001 Karbala, Iraq \\ Bahaa.hussain@uokerbala.edu.iq, ali_altohmazy44@yahoo.com,sah246@gmail.com
}

\begin{abstract}
This study presents a knowledge on the shape modes behavior of steel IPE300 castellated section with square and hexagonal opening. These sections may be used as beams, columns or beam-columns member. The first four modes of failure will governing the use and application of these sections in the multistory building or bridges. Castellated technique become a promising technology for increasing flexural and shear strength of the same section without any additional material or weight this due to increase the depth of the section (by cutting the proper shape). A 3D numerical model was carried out by finite element program Abaqus to explore the performance of castellated IPE300 section under various types of loading. A parametric study also was prepared to focus on fundamental time period and mode shape. The obtained results indicated that a significant increasing in frequency by about a $28.3 \%$ due to increasing in the flexural bending stiffness of the castellated beams comparing with original reference beam.
\end{abstract}

Key words: Modal, castellated, frequency, mode shapes, beam, bridges

\section{INTRODUCTION}

The primarily tool is modal analysis for deriving dependable simulations to represent the dynamic behavior of structure. Generally, it may be held that the applications of modal analysis cover a wide-ranging of intents (Silva, 1999).

Gustavo et al. (2006), focus on recognize the region where the opening with a choosing size and shape does not cause decrease on the beam strength. Knowing the position of this region, called the "neutral zone".

Wakchaure et al. (2012), studied the parametric study on different depth of castellated beams with different opening. Their results showed that the openings with 0.6 of the beam depth is the possible maximum openings. Bajoria et al. (2010), used the finite element package ANSYS to prepare free vibration modal analysis of the conventional pallet racking systems. They conclude that the percentage difference between times period of frames made up from original open section is less as compared to frames made up from torsionally strengthened sections. Al-Khafaji and Al-Abbas (2016), studied the effect of multi shaped web opening on the behavior of steel beams. They concluded that applying CFRP plates round the web opening of steel IPE sections was an effective technique for increasing the load capacity and decreasing the deflections. Recently, Klimenda and Soukup (2017), studied the modal analysis of thin aluminum plate. Their research was done numerically by ANSYS finite element program their main conclusion was with increasing number of shapes cause increase in the natural frequencies of the shape and some eigen-shapes have the same natural frequency. The aim of the present study is to identify the natural frequency and mode shapes of the system.

\section{Finite element analysis}

Modeling: The primary requirement of the FEA is the geometry of the part which is generated by using AutoCAD to help in the creation the geometry very accurately with the user friendly commands for the better model. After the modelling, the geometry can be export to the Abaqus to define material, sections, boundary conditions, meshing and continue with analysis. The quadrilateral mesh elements are assigned the S4R element type with six DOF per node, i.e., translations and rotations on the $\mathrm{X}-\mathrm{Z}$ axis was adopted (Fig. 1).

Modal analysis is one of the dynamic analysis, the inertia of the system was consider at solution. An one degree of freedom mechanical system is drawn in Fig. 2. The scheme is considered by weight of the system $\mathrm{m}$, damping $\mathrm{c}$, stiffness $\mathrm{k}$ and excitation force $\mathrm{F}(\mathrm{t})$. Figure 2 show the well-known equation of motion which can be written as:

Corresponding Author: Bahaa Hussein Al-Abbas, College of Engineering, University of Kerbala, 56001 Karbala, Iraq, Bahaa.hussain@uokerbala.edu.iq 


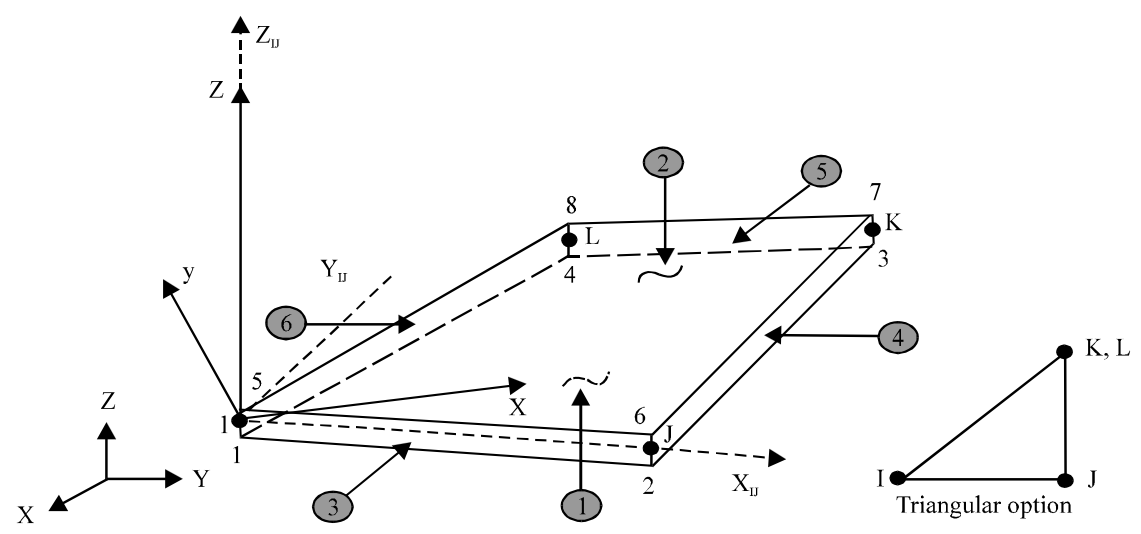

Fig. 1: Geometry of element (S4R)

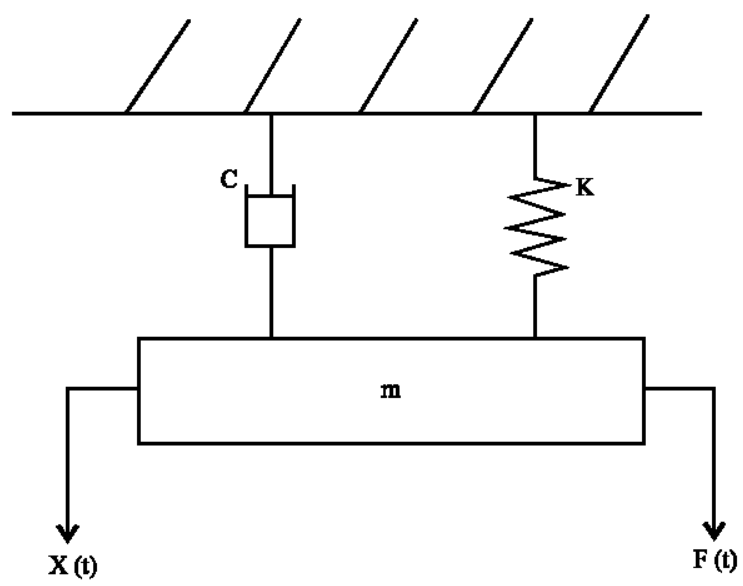

Fig. 2: One degree of freedom scheme

$$
m \cdot \frac{d^{2} x}{d t^{2}}+c \cdot \frac{d x}{d t}+k \cdot x(t)=F(t)
$$

Where:

$\mathrm{x}(\mathrm{t})=$ The deflection at any time

$\mathrm{dx} / \mathrm{dt}=$ The speed

$\mathrm{d}^{2} \mathrm{x} / \mathrm{dt}^{2}=$ The acceleration

$\mathrm{F}(\mathrm{t}) \quad=$ The excitation force

If the excitation force equal to zero and damping was neglected, the Eq. 1 may be rewritten as:

$$
m \cdot \frac{d^{2} x}{d t^{2}}+k \cdot x(t)=0
$$

This is second order linear homogeneous differential equation which is can be solved directly with initial conditions as $(0)=\mathrm{x}_{0}, \mathrm{x}^{\prime}(0)=\mathrm{x}^{\prime} 0$ :

$$
x(t)=c \sin \left(\omega_{n} t+\varphi\right)
$$

Where:

$\omega_{\mathrm{n}}=$ The angular natural frequency $=\sqrt{\mathrm{k}}$

$\mathrm{C}=$ The amplitude $=\sqrt{\left(\frac{\mathrm{x}_{0}}{\omega_{\mathrm{n}}}\right)^{2}+\mathrm{x}_{0}{ }^{2}} \quad \sqrt{\frac{\mathrm{k}}{\mathrm{m}}}$
$\varphi=$ Phase angle $=\operatorname{arctg} \frac{\mathrm{x}_{0} \cdot \omega_{\mathrm{n}}}{\mathrm{x}_{0}}$

The system oscillates with natural frequency $\omega_{\mathrm{n}}$. Each value of the natural frequency matches one's eigen mode shape. Equation 3 can be changes to the matrix form as:

$$
\mathrm{M} \ddot{\mathrm{x}}+\mathrm{Kx}(\mathrm{t})=0
$$

Where:

$\mathrm{M}=$ The mass matrix

$\mathrm{K}=$ The stiffness matrix

$\mathrm{x}(\mathrm{t})=$ The displacement vector

$\ddot{x}(t)=$ The acceleration vector

Displacement and acceleration can be written as:

$$
\begin{gathered}
x(t)=y e^{i \alpha t} \\
\ddot{x}(t)=-\omega^{2} y e^{i \alpha t}
\end{gathered}
$$

where, $\mathrm{y}$ is the eigenvector of system. After substitute Eq. 5 and 6 into Eq. 4, results:

$$
\left(-\omega^{2} \mathrm{M}+\mathrm{K}\right) \mathrm{ye}^{\mathrm{i} \alpha \mathrm{t}}=0
$$

By modifying Eq. 7, becomes:

$$
(\mathrm{K}-\lambda \mathrm{M}) \mathrm{y}=0
$$


where, $\lambda$ is the eigen values that can be calculated for a nontrivial solutions if and only if: $|\mathrm{K}-\lambda \mathrm{M}|=0$. Each eigenvalue $\lambda$ have their corresponding eigen vectory.

\section{MATERIALS AND METHODS}

A greatly simpler material to be modeled is steel, since, the physical characteristics of it are well known and widely used. The density and modules of elasticity and poisons ratio defined as indicated in Table 1 .

Sections and geometry: The original beam is IPE300 has the properties as listed in Table 2 a length of $3 \mathrm{~m}$ was used with fixed at one end and the other was free. The study focus to keep the weight of material is fixed approximately for all specimens as noticed in Fig. 3 and Table 3.

Mesh size: The effect of mesh size was studied by reducing the mesh size from $100-25 \mathrm{~mm}$ for the reference original beam IPE300. The eigen values and the corresponding frequency of first mode for each mesh size are listed in Table 4.

Table 1: Material properties of steel

\begin{tabular}{lcc}
\hline Density $\left(\mathrm{kg} / \mathrm{mm}^{3}\right)$ & Young modulus $\left(\mathrm{N} / \mathrm{mm}^{2}\right)$ & Poisons ratio \\
\hline $7.8 \mathrm{E}-9$ & 200000 & 0.3
\end{tabular}

It can be noticed that the natural frequency identified by a mesh size of $25 \mathrm{~mm}$ divisions is useful for the analysis procedure. It saves time and only varies approximately $0.02 \%$ from the predicted values of a mesh size of $10 \mathrm{~mm}$.

\section{RESULTS AND DISCUSSION}

Finite element analysis was prepared for nine cantilever beams. One is the control original beam four of them have square opening castellated beams and the other four have hexagonal opening.

Frequency: Table 5 shows the first five eigen values and the corresponding frequencies for all types of beams. It is clearly noticed that the first mode frequency of original beam is larger than all the castellated beam of course because the first mode is the lateral bending mode about the week axis, since, the increasing in width is not significant comparing with depth. Also, this done by the second mode, since, the second mode shape is the torsional mode.

Mode shapes: The first 4 modes shape were remarked in the present study including lateral bending, torsion, strong axis bending and buckling are drawn in Fig. 4-8.

Table 2: Properties of section IPE300

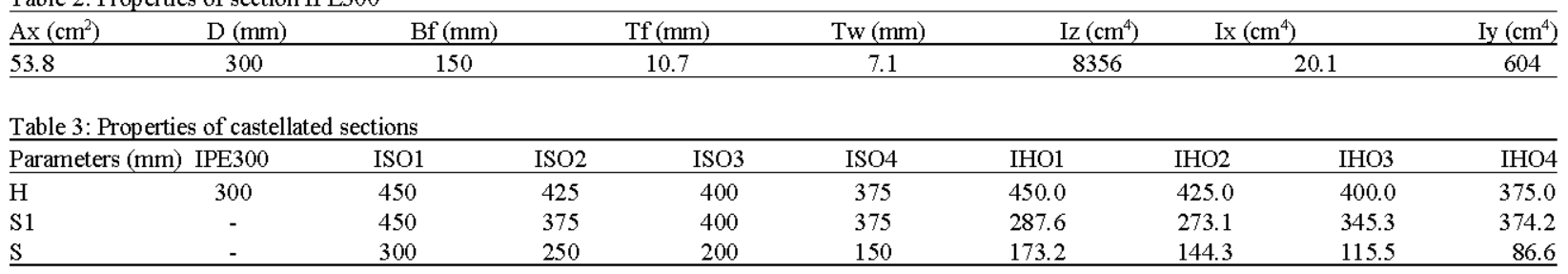

Specimen Suffixes: $=\mathrm{SO}=$ Square Opening; $\mathrm{HO}=$ Hexagonal Opening

Table 4: Effect of mesh size

\begin{tabular}{lccc}
\hline Mesh size $(\mathrm{mm})$ & No.of elements & Eigen values & Frequency $(\mathrm{Hz})$ \\
\hline 100 & 210 & 3304.8 & 09.149 \\
75 & 320 & 3298.7 & 09.141 \\
50 & 720 & 3899.3 & 09.938 \\
37.5 & 1280 & 4109.4 & 10.203 \\
25 & 2880 & 4257.5 & 10.385 \\
10 & 18000 & 4301.6 & 10.383 \\
\hline
\end{tabular}

Table 5: Frequency $(\mathrm{Hz})$

\begin{tabular}{|c|c|c|c|c|c|c|c|c|c|}
\hline Mode \# & IPE300 & ISO1 & ISO2 & ISO3 & ISO4 & IHO1 & $\mathrm{IHO} 2$ & IHO3 & IHO4 \\
\hline Lateral bending & 10.385 & 10.013 & 10.114 & 10.138 & 10.200 & 10.112 & 10.160 & 10.147 & 10.186 \\
\hline Torsional mode & 17.817 & 14.608 & 14.936 & 15.336 & 15.806 & 14.569 & 14.911 & 15.326 & 15.811 \\
\hline Bending mode & 39.089 & 45.369 & 47.192 & 47.111 & 45.824 & 50.186 & 49.969 & 48.595 & 46.610 \\
\hline Buckling mode & 63.538 & 58.310 & 59.407 & 60.249 & 61.070 & 58.337 & 59.403 & 60.175 & 61.008 \\
\hline 2nd torsional & 80.837 & 74.955 & 75.472 & 76.210 & 77.100 & 74.777 & 75.384 & 76.179 & 77.118 \\
\hline 2nd Buckling & 153.430 & 84.683 & 90.506 & 98.422 & 107.290 & 81.870 & 88.484 & 97.280 & 107.200 \\
\hline Combined torsion and bending & 164.570 & 104.390 & 109.870 & 115.820 & 121.860 & 102.660 & 108.370 & 114.660 & 121.450 \\
\hline Combined torsion and buckling & 190.430 & 121.800 & 129.160 & 137.170 & 145.350 & 120.760 & 128.010 & 136.260 & 145.190 \\
\hline
\end{tabular}


(a)

(a)

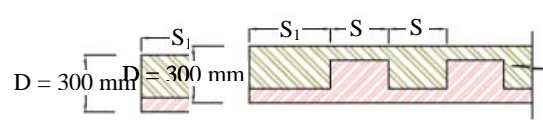

(c)

(c)

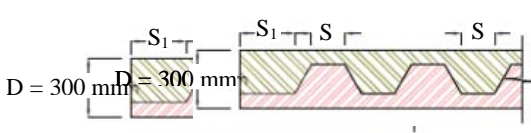

(b)

(b)

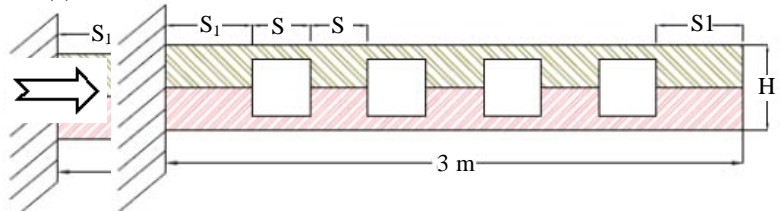

(d) (d)

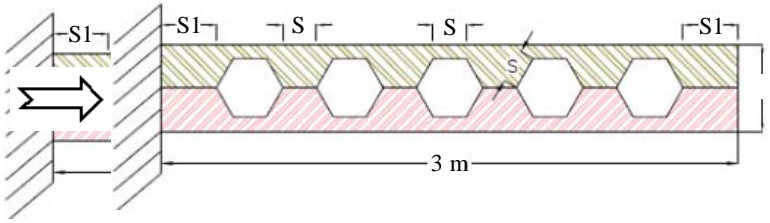

Fig. 3: Sections and geometry of original and castellated beam; a) Original beam IPE300; b) Castellated beam with square opening; c) Original beam IPE300 and d) Castellated beam with hexagonal opening

(a)

$$
\begin{gathered}
\mathrm{U}, \text { magnitude } \\
+1.000 \mathrm{e}+00 \\
+9.167 \mathrm{e}-01 \\
+8.333 \mathrm{e}-01 \\
+7.500 \mathrm{e}-01 \\
+6.667 \mathrm{e}-01 \\
+5.833 \mathrm{e}-01 \\
+5.000 \mathrm{e}-01 \\
+4.167 \mathrm{e}-01 \\
+3.333 \mathrm{e}-01 \\
+2.500 \mathrm{e}-01 \\
+1.667 \mathrm{e}-01 \\
+8.333 \mathrm{e}-02 \\
+0.000 \mathrm{e}+00
\end{gathered}
$$

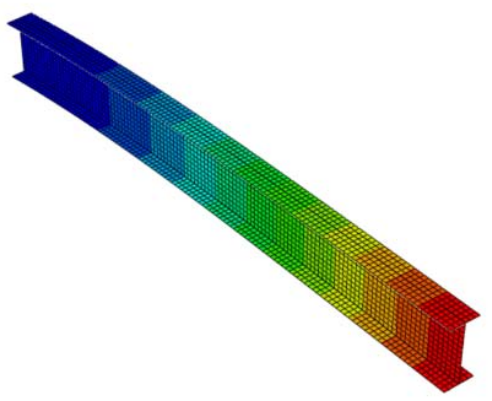
Y ODB: Modal-IPE300.odb Abaqus/Standard 3D experience R2016x Tue Dec 11 22:31:35 Arabic
standard time
Step: Freq.
Mode 1: value $=4257.5$ Freq. $=10.385$ (cycles/time)
Primary Var: U, magnitude

(b)

$\mathrm{U}$, magnitude

$+1.102 \mathrm{e}+00$

$+1.011 \mathrm{e}-01$

$+9.187 \mathrm{e}-01$

$+8.268 \mathrm{e}-01$

$+7.349 \mathrm{e}-01$

$+6.431 \mathrm{e}-01$

$+5.512 \mathrm{e}-01$

$+4.593 \mathrm{e}-01$

$+3.675 \mathrm{e}-01$

$+2.756 \mathrm{e}-01$

$+1.837 \mathrm{e}-01$

$+9.187 \mathrm{e}-02$

$+0.000 \mathrm{e}+00$

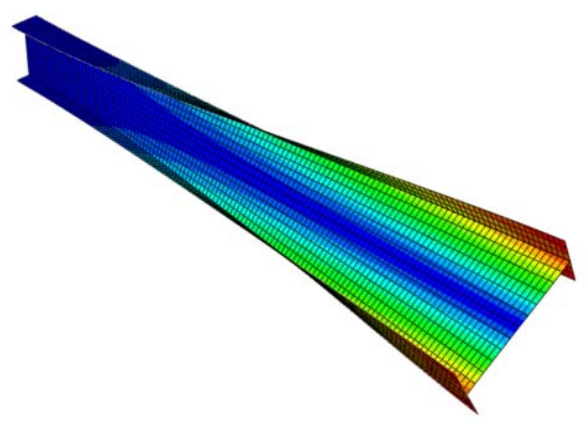

$z \stackrel{x}{x}$

ODB: Modal-IPE300.odb Abaqus/Standard 3D experience R2016x Tue Dec 11 22:31:35 Arabic standard time

Step: Freq.

Mode 2 : value $=12532$. Freq. $=17.817$ (cycles/time $)$

Primary Var: U, magnitude

Fig. 4: First and second modes of IPE300 
(a)

U, magnitude

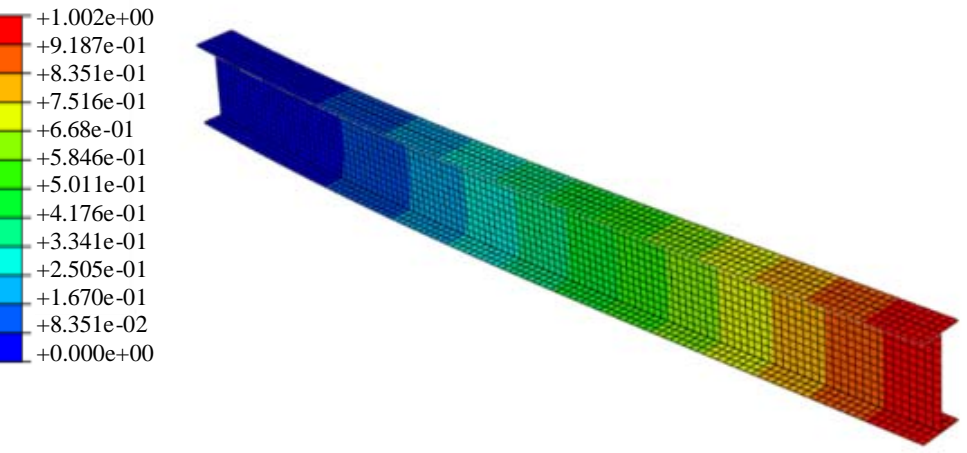

ODB: Modal-IPE300.odb Abaqus/Standard 3D experience R2016x Tue Dec 11 22:31:35 Arabic standard time Step: Freq.

Mode 3: value $=60323$. Freq. $=39.089($ cycles/time $)$

Primary Var.: U, Magnitude

(b)

$\mathrm{U}$, magnitude

$+1.000 \mathrm{e}+00$

$+9.167 \mathrm{e}-01$

$+8.333 \mathrm{e}-01$

$+7.500 \mathrm{e}-01$

$+6.667 \mathrm{e}-01$

$+5.833 \mathrm{e}-01$

$+5.000 \mathrm{e}-01$

$+4.167 \mathrm{e}-01$

$+3.333 \mathrm{e}-01$

$+2.500 \mathrm{e}-01$

$+1.667 \mathrm{e}-01$

$+8.333 \mathrm{e}-02$

$+0.000 \mathrm{e}+00$

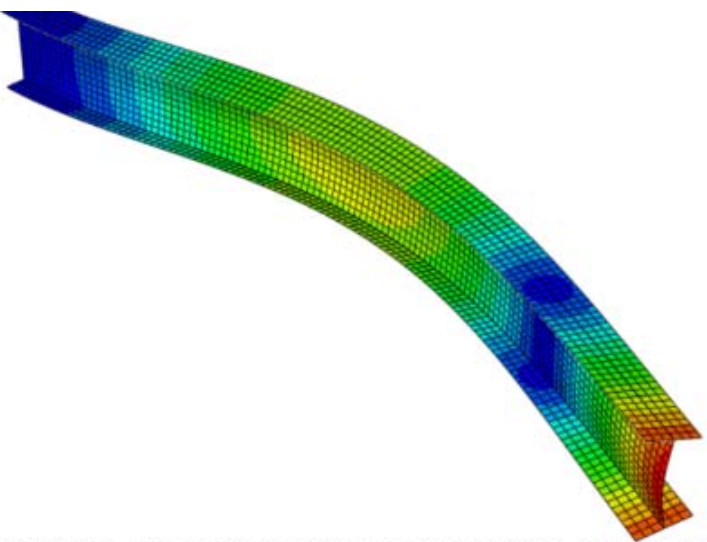

Y ODB: Modal-IPE300.odb Abaqus/Standard 3D experience R2016x Tue Dec 11 22:31:35 Arabic standard time Step: Freq.

Mode 4: value $=1.59379 \mathrm{E}+05$ Freq. $=63.538($ cycles $/$ time $)$

Primary Var: U, magnitude

(c)

$\mathrm{U}$, magnitude

$+1.071 \mathrm{e}+00$

$+9.816 \mathrm{e}-01$

$+8.924 \mathrm{e}-01$

$+7.139 \mathrm{e}-01$

$+6.247 \mathrm{e}-01$

$+5.345 \mathrm{e}-01$

$+4.462 \mathrm{e}-01$

$+3.570 \mathrm{e}-01$

$+2.677 \mathrm{e}-01$

$+1.785 \mathrm{e}-01$

$+8.924 \mathrm{e}-01$

$+8.924 \mathrm{e}-02$

$+0.000 \mathrm{e}+00$
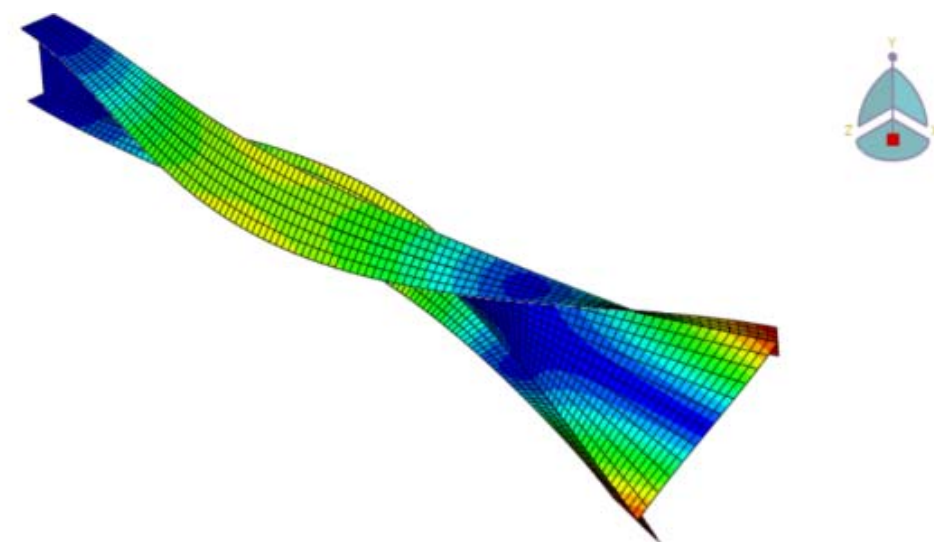

Y ODB: Modal-IPE300.odb Abaqus/Standard 3D experience R2016x Tue Dec 11 22:31:35 Arabic standard time Step: Freq.

Mode 5: value $=2.57976 \mathrm{E}+05$ Freq. $=80.837($ cycles $/$ time $)$

Primary Var: U, Magnitude

Fig. 5: Third, fourth and fifth modes of IPE300 
(a)

$\mathrm{U}$, magnitude
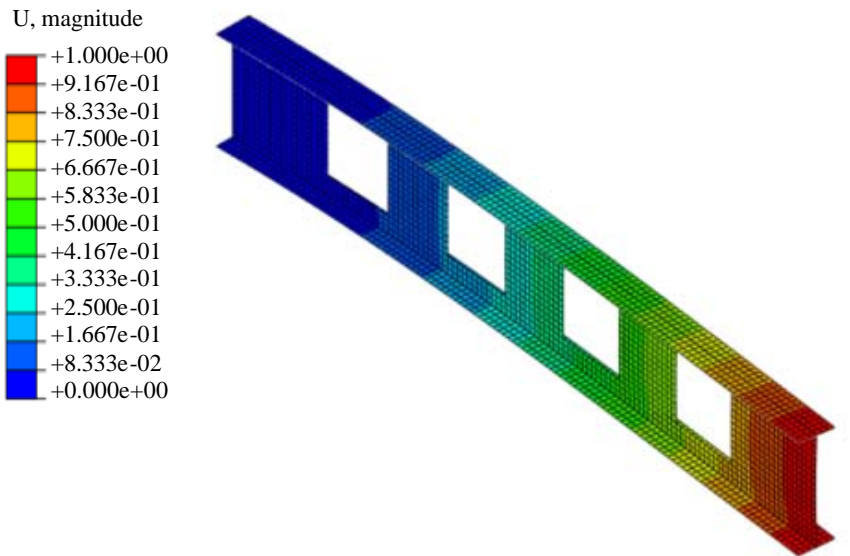

ODB: Modal-IS1.odb Abaqus/Standard 3D experience R2016x Sun Dec 09 18:53:13 Arabic standard time 20; Step:
Freq; Mode 1: value $=3957.7$ Freq $=10.013$ (cycles/time)
$\mathbf{Z}$ Primary Var.: U, magnitude

(b)

$\mathrm{U}$, magnitude
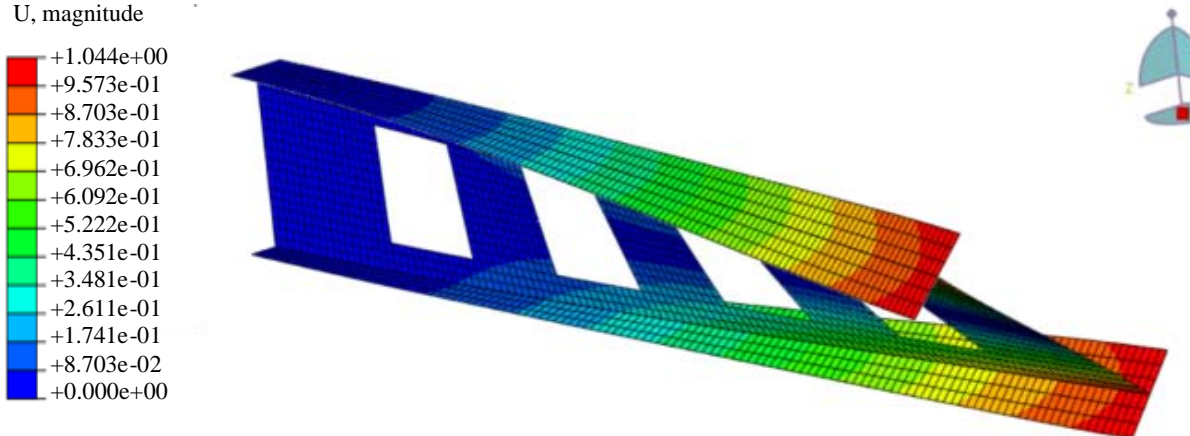

ODB: Modal-IS1.odb Abaqus/Standard 3D experience R2016x Sun Dec 09 18:53:13 Arabic standard time 20; Step Freq; Mode 2: value $=8424.0$ Freq. $=14.608($ cycles $/$ time $)$ Primary Var.: U, magnitude

(c)

$\mathrm{U}$, magnitude

$+1.002 \mathrm{e}+00$

$+9.187 \mathrm{e}-01$

$+8.352 \mathrm{e}-01$

$+7.517 \mathrm{e}-01$

$+6.682 \mathrm{e}-0$

$+5.846 \mathrm{e}-01$

$+5.011 \mathrm{e}-01$

$+4.176 \mathrm{e}-0$

$+3.341 \mathrm{e}-0$

$+2.506 \mathrm{e}-0$

$+1.670 \mathrm{e}-0$

$+8.352 \mathrm{e}-02$

$+0.000 \mathrm{e}+00$

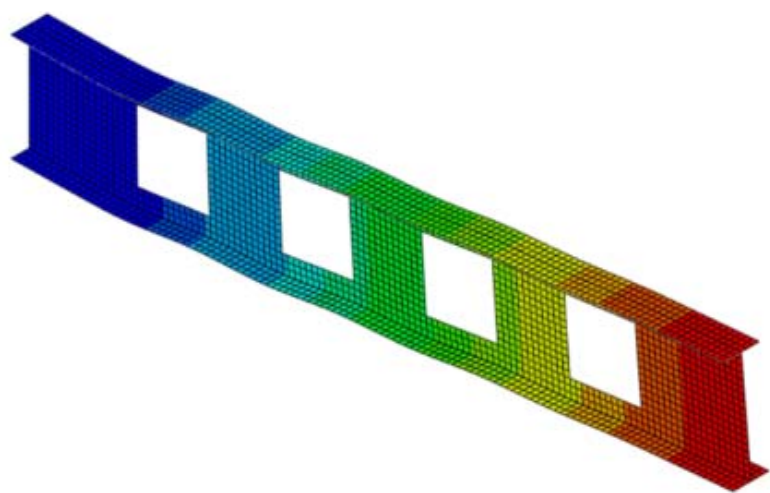

ODB: Modal-IS1.odb Abaqus/Standard 3D experience R2016x Sun Dec 09 18:53:13 Arabic standard time 20; Step: Freq. Mode 3: value $=81259$, Freq $=45.369$ (cycles $/$ time $)$

Primary Var: U, magnitude

Fig. 6: First, second and third modes of ISO1 
(a)
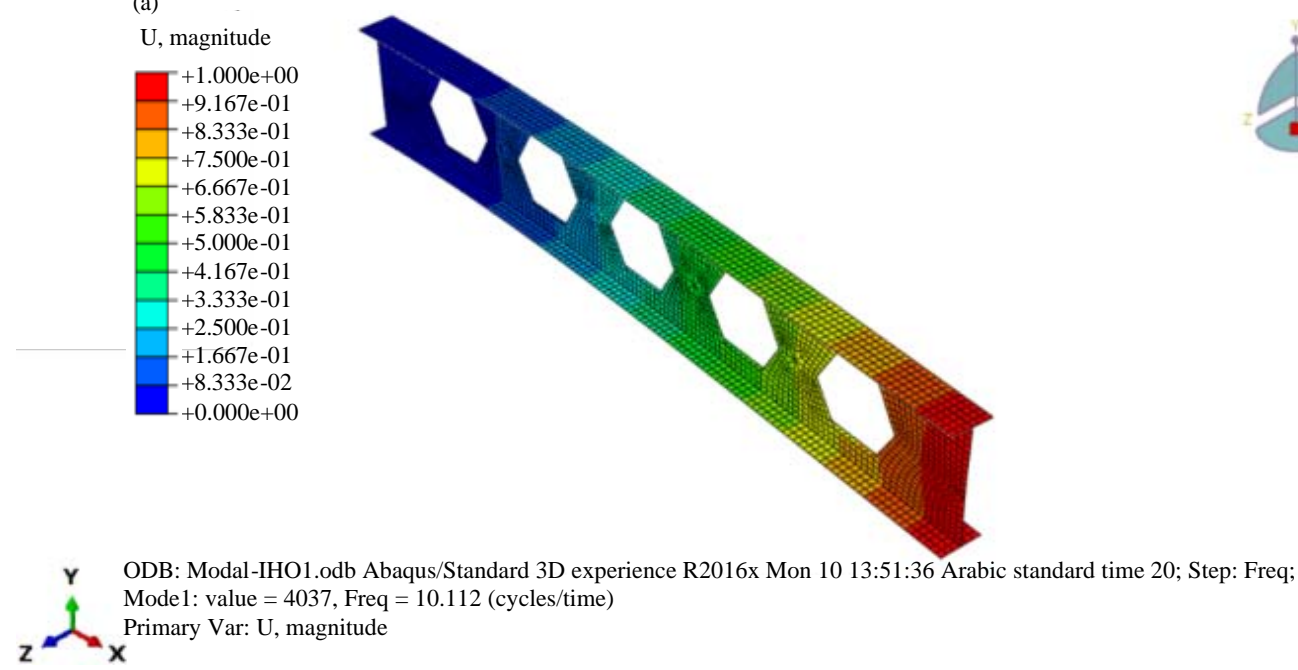

(b)

$\mathrm{U}$, magnitude
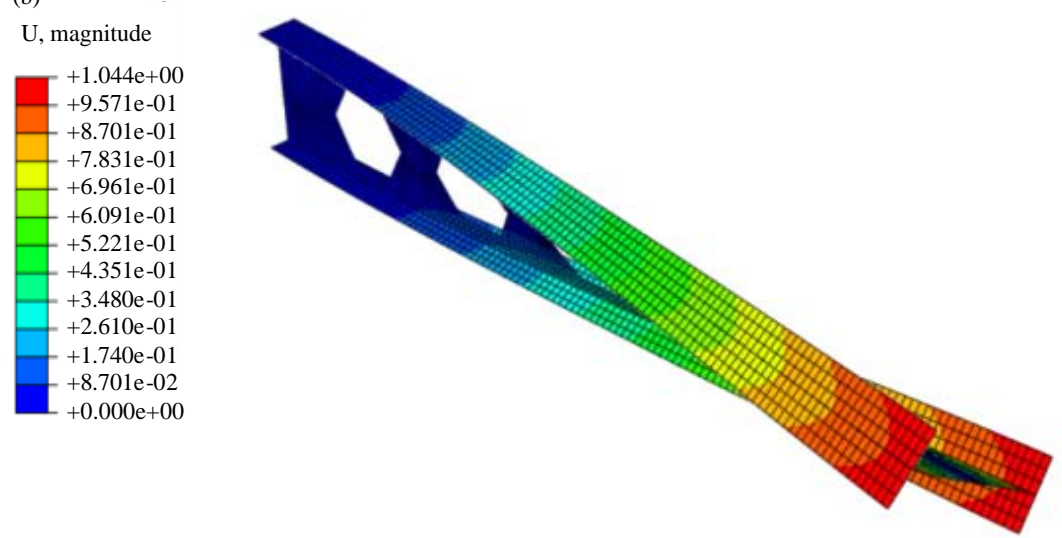
Y ODB: Modal-IHO1.odb Abaqus/Standard 3D experience R2016x Mon 10 13:51:36 Arabic standard time 20; Step: FREQ; Mode 2: value $=8379.8$, Freq. $=14.569($ cycles $/$ time $)$ Primary Var.: U, magnitude
$z \sim x$

(c)

U, magnitude
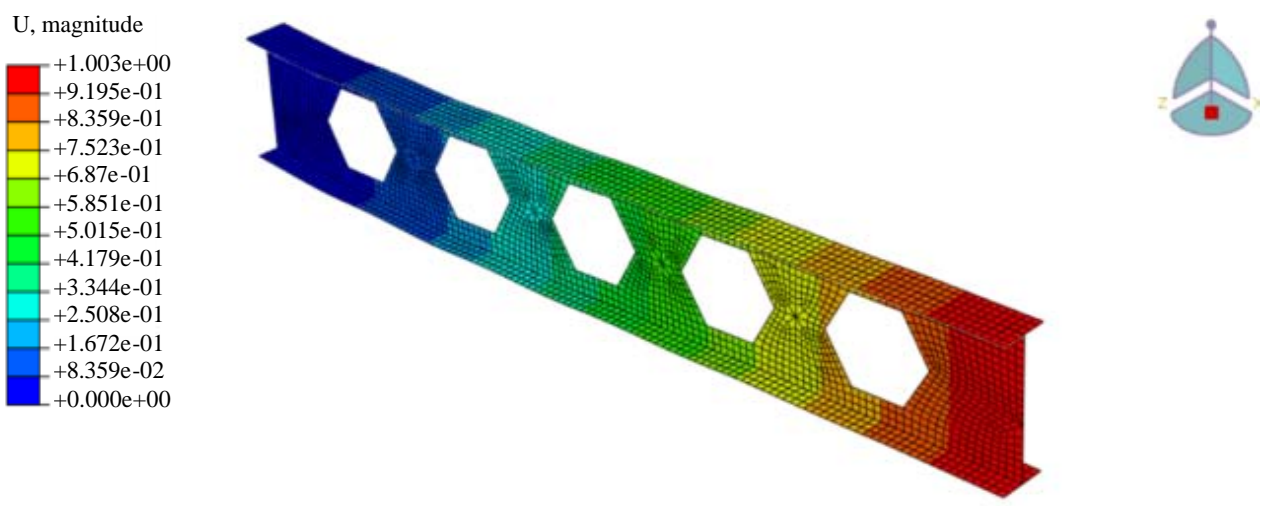

ODB: Modal-IHO1.odb Abaqus/Standard 3D experience R2016x Mon 10 13:51:36 Arabic standard time 20; Step: Freq; Mode $3:$ value $=99431$, Freq. $=50.186($ cycles $/$ time $)$ Primary Var: U, magnitude<smiles>[Z]C([Z])C([Z])[X]</smiles>

Fig. 7: First, second and third modes of IHO1 


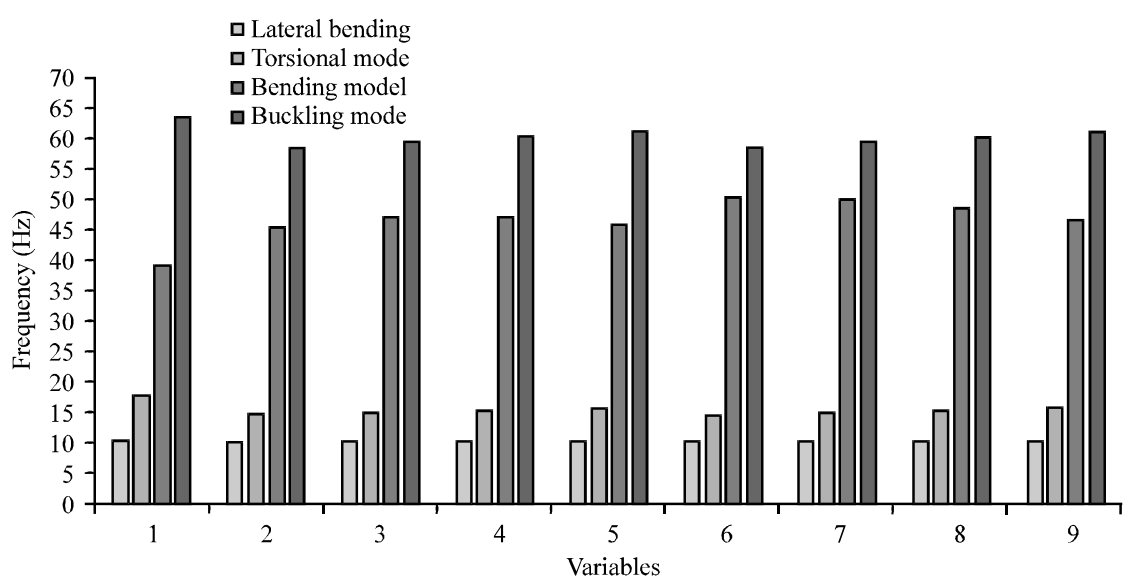

Fig. 8: Frequency of first four modes of reference and castellated beams

\section{CONCLUSION}

Based on the numerical results acquired in the present study, some points can be concluded and summarize as follow: the obtained results indicated that a significant reduction in frequency due to decreasing in lateral flexural stiffness of the steel beams for the first mode shape of all castellated beams.

Generally, hexagonal web opening were caused larger increasing in stiffness than square opening by about a $28.3 \%$ with respect to the strong bending mode (3rd mode).

Only the third mode was gain benefit results of frequency and stiffness, therefore, it is not recommend that use these castellated beams when the main loads are axial, lateral or torsional.

\section{REFERENCES}

AL-Khafaji, A.G.A. and B.H. Al-Abbas, 2016. Numerical study on the effect of openings in steel ipe beams strengthened by cfrp plats. J. Kerbala Univ., 14: 213-227.
Al-Abbas, B., S.A. Hemzah and W. Alyhya, 2018. Finite difference derivation and finite element technique of annular plate buckling under axial and shear loads. Intl. J. Civil Eng. Technol., 9: 32-41.

Bajoria, K.M., K.K. Sangle and R.S. Talicotti, 2010. Modal analysis of cold-formed pallet rack structures with semi-rigid connections. J. Constr. Steel Res., 66: 428-441.

Gustavo, D.S., H.F. Ricardo and C.L. Jose, 2006. Design aids for unreinforced web openings in steel and composite beams with W-shapes. Eng. J. Am. Inst. Steel Constr., 43: 163-172.

Klimenda, F. and J. Soukup, 2017. Modal analysis of thin aluminium plate. Procedia Eng., 177: 11-16.

Silva, J.M.E., 1999. An Overview of the Fundamentals of Modal Analysis. In: Modal Analysis and Testing, Silva, J.M.M. and N.M.M. Maia, (Eds.). Springer, Berlin, Germany, ISBN:9780792358930, pp: $1-34$.

Wakchaure, M.R., A.V. Sagade and V.A. Auti, 2012. Parametric study of castellated beam with varying depth of web opening. Intl. J. Sci. Res. Publ., 2: 2250-3153. 